\title{
General Viscosity Approximation Methods for Common Fixed Points of Nonexpansive Semigroups in Hilbert Spaces
}

\author{
Xue-song Li, ${ }^{1}$ Nan-jing Huang, ${ }^{1}$ and Jong Kyu Kim ${ }^{2}$ \\ ${ }^{1}$ Department of Mathematics, Sichuan University, Chengdu, Sichuan 610064, China \\ 2 Department of Mathematics, Kyungnam University, Masan, Kyungnam 631-701, Republic of Korea \\ Correspondence should be addressed to Jong Kyu Kim, jongkyuk@kyungnam.ac.kr \\ Received 12 November 2010; Accepted 17 December 2010 \\ Academic Editor: Jen Chih Yao
}

Copyright (C) 2011 Xue-song Li et al. This is an open access article distributed under the Creative Commons Attribution License, which permits unrestricted use, distribution, and reproduction in any medium, provided the original work is properly cited.

This paper is devoted to the strong convergence of two kinds of general viscosity iteration processes for approximating common fixed points of a nonexpansive semigroup in Hilbert spaces. The results presented in this paper improve and generalize some corresponding results in (X. Li et al., 2009, S. Li et al., 2009, and Marino and Xu, 2006).

\section{Introduction}

Let $H$ be a real Hilbert space and $A$ be a linear bounded operator on $H$. Throughout this paper, we always assume that $A$ is strongly positive; that is, there exists a constant $\bar{\gamma}>0$ such that

$$
\langle A x, x\rangle \geq \bar{\gamma}\|x\|^{2}, \quad \forall x \in H .
$$

We recall that a mapping $T: H \rightarrow H$ is said to be contractive if there exists a constant $\alpha \in[0,1)$ such that $\|T x-T y\| \leq \alpha\|x-y\|$ for all $x, y \in H . T: H \rightarrow H$ is said to be

(i) nonexpansive if

$$
\|T x-T y\| \leq\|x-y\|, \quad \forall x, y \in H
$$


(ii) $L$-Lipschitzian if there exists a constant $L>0$ such that

$$
\|T x-T y\| \leq L\|x-y\|, \quad \forall x, y \in H
$$

(iii) pseudocontractive if

$$
\langle T x-T y, x-y\rangle \leq\|x-y\|^{2}, \quad \forall x, y \in H
$$

(iv) $\phi$-strongly pseudocontractive if there exists a strictly increasing function $\phi$ : $[0,+\infty) \rightarrow[0,+\infty)$ with $\phi(0)=0$ such that

$$
\langle T x-T y, x-y\rangle \leq\|x-y\|^{2}-\phi(\|x-y\|)\|x-y\|, \quad \forall x, y \in H
$$

It is obvious that pseudocontractive mapping is more general than $\phi$-strongly pseudocontractive mapping. If $\phi(r)=\alpha r$ with $0<\alpha \leq 1$, then $\phi$-strongly pseudocontractive mapping reduces to $\beta$-strongly pseudocontractive mapping with $1-\alpha=\beta \in[0,1)$, which is more general than contractive mapping.

A nonexpansive semigroup is a family

$$
\Gamma:=\{T(s): s \geq 0\}
$$

of self-mappings on $H$ such that

(1) $T(0)=I$, where $I$ is the identity mapping on $H$;

(2) $T(s+t) x=T(s) T(t) x$ for all $x \in H$ and $s, t \geq 0$;

(3) $T(s)$ is nonexpansive for each $s \geq 0$;

(4) for each $x \in H$, the mapping $T(\cdot) x$ from $R^{+}$into $H$ is continuous.

We denote by $F(\Gamma)$ the common fixed points set of nonexpansive semigroup $\Gamma$, that is,

$$
F(\Gamma)=\bigcap_{s \geq 0} F(T(s))=\{x \in H: T(s) x=x \quad \text { for each } s \geq 0\} .
$$

In the sequel, we always assume that $F(\Gamma) \neq \emptyset$.

In recent decades, many authors studied the convergence of iterative algorithms for nonexpansive mappings, nonexpansive semigroup, and pseudocontractive semigroup in Banach spaces (see, e.g., [1-15]). Let $f: H \rightarrow H$ be a contractive mapping with coefficient $\alpha \in(0,1), T: H \rightarrow H$ be a nonexpansive mapping, and $A$ be a strongly positive and linear bounded operator with coefficient $\bar{\gamma}>0$. Let $F$ denote the fixed points set of $T$. Recently, Marino and $\mathrm{Xu}[6]$ considered the general viscosity approximation process as follows:

$$
x_{t}=(I-t A) T x_{t}+\operatorname{tr} f\left(x_{t}\right),
$$


where $t \in(0,1)$ such that $t<\|A\|^{-1}$ and $0<\gamma<\bar{\gamma} / \alpha$. Marino and $\mathrm{Xu}$ [6] proved that the sequence $\left\{x_{t}\right\}$ generated by (1.8) converges strongly as $t \rightarrow 0$ to the unique solution of the variational inequality

$$
\left\langle(A-\gamma f) x^{*}, x-x^{*}\right\rangle \geq 0, \quad \forall x \in F,
$$

which is the optimality condition for the minimization problem

$$
\min _{x \in F} \frac{1}{2}\langle A x, x\rangle+h(x)
$$

where $h$ is a potential function for $\gamma f$, that is, $h^{\prime}(x)=\gamma f(x)$ for all $x \in H$.

Let $\Gamma:=\{T(s): s \geq 0\}$ be a nonexpansive semigroup on $H$ and $f: H \rightarrow H$ be a contractive mapping with coefficient $\alpha \in(0,1)$. Very recently, S. Li et al. [5] considered the following general viscosity iteration process:

$$
x_{n}=\left(I-\alpha_{n} A\right) \frac{1}{t_{n}} \int_{0}^{t_{n}} T(s) x_{n} d s+\alpha_{n} \gamma f\left(x_{n}\right), \quad \forall n \geq 1,
$$

where $\left\{\alpha_{n}\right\} \subset(0,1]$ and $\left\{t_{n}\right\}$ are two sequences satisfying certain conditions. S. Li et al. [5] claimed that the sequence $\left\{x_{n}\right\}$ generated by (1.11) converges strongly as $t_{n} \rightarrow \infty$ to $x^{*} \in$ $F(\Gamma)$ which solves the following variational inequality:

$$
\left\langle(A-\gamma f) x^{*}, x-x^{*}\right\rangle \geq 0, \quad \forall x \in F(\Gamma) .
$$

More research work related to general viscosity iteration processes for nonexpansive mapping and nonexpansive semigroup can be found (see, e.g., $[5,6,12]$ ).

An interesting work is to extend some results involving general viscosity approximation processes for nonexpansive mapping, nonexpansive semigroup, and contractive mapping to nonexpansive semigroup and $\phi$-strongly pseudocontractive mapping (pseudocontractive mapping, resp.). Motivated by the works mentioned above, in this paper, on one hand we study the convergence of general implicit viscosity iteration process (1.11) constructed from the nonexpansive semigroup $\Gamma:=\{T(t): t \geq 0\}$ and $\phi$-strongly pseudocontractive mapping (pseudocontractive mapping, resp.) in Hilbert spaces. On the other hand, we consider the convergence of the following general viscosity iteration process:

$$
x_{n}=\left(I-\alpha_{n} A\right) T\left(t_{n}\right) x_{n}+\alpha_{n} \gamma f\left(x_{n}\right), \quad \forall n \geq 1,
$$

where $\alpha_{n} \in(0,1], \gamma>0, T\left(t_{n}\right) \in \Gamma$ and $f$ is a $\phi$-strongly pseudocontractive mapping (pseudocontractive mapping, resp.). The results presented in this paper improve and generalize some corresponding results in [4-6]. 


\section{Preliminaries}

A mapping $T$ with domain $D(T)$ and range $R(T)$ in $H$ is said to be demiclosed at a point $p \in H$ if $\left\{x_{n}\right\}$ is a sequence in $D(T)$ which converges weakly to $x \in D(T)$ and $\left\{T x_{n}\right\}$ converges strongly to $p$, then $T x=p$.

For the sake of convenience, we restate the following lemmas that will be used.

Lemma 2.1 (see [6]). Let A be a strongly positive and linear bounded operator on a real Hilbert space $H$ with coefficient $\bar{\gamma}>0$ and $0<\rho \leq\|A\|^{-1}$. Then $\|I-\rho A\| \leq 1-\rho \bar{\gamma}$.

Lemma 2.2 (see [16]). Let $E$ be a Banach space and $T: E \rightarrow E$ be a $\phi$-strongly pseudocontractive and continuous mapping. Then $T$ has a unique fixed point in $E$.

Lemma 2.3 (see [9]). Let E be a uniformly convex Banach space, K a nonempty closed convex subset of $E$ and $T: K \rightarrow E$ a nonexpansive mapping. Then $I-T$ is demiclosed at zero.

Lemma 2.4 (see [10]). Let $C$ be a nonempty bounded closed convex subset of a real Hilbert space $H$ and $\Gamma=\{T(s): s \geq 0\}$ be a nonexpansive semigroup on $H$. Then for any $h \geq 0$,

$$
\limsup _{t \rightarrow \infty}\left\|\frac{1}{x \in C} \int_{0}^{t} T(s) x d s-T(h)\left(\frac{1}{t} \int_{0}^{t} T(s) x d s\right)\right\|=0 .
$$

\section{Main Results}

We first discuss the convergence of general implicit viscosity iteration process (1.11) constructed from a nonexpansive semigroup $\Gamma:=\{T(s): s \geq 0\}$.

Theorem 3.1. Let $\Gamma:=\{T(s): s \geq 0\}$ be a nonexpansive semigroup on $H$ and $f: H \rightarrow H$ be an $L_{f}$-Lipschitzian $\phi$-strongly pseudocontractive mapping with $\lim _{t \rightarrow+\infty} \phi(t)=+\infty$. Let $A$ be a strongly positive and linear bounded operator on $H$ with coefficient $\bar{\gamma}$. Then for any $0<\gamma \leq \bar{\gamma}$, the sequence $\left\{x_{n}\right\}$ generated by (1.11) is well defined. Suppose that

$$
\lim _{t \rightarrow \infty} \alpha_{n}=0, \quad \lim _{n \rightarrow \infty} t_{n}=\infty
$$

Then the sequence $\left\{x_{n}\right\}$ converges strongly as $n \rightarrow \infty$ to a common fixed point $x^{*} \in F(\Gamma)$ that is the unique solution in $F(\Gamma)$ to variational inequality $(V I)$ :

$$
\left\langle\gamma f\left(x^{*}\right)-A x^{*}, x^{*}-p\right\rangle \geq 0, \quad \forall p \in F(\Gamma)
$$

Proof. Since $\lim _{n \rightarrow \infty} \alpha_{n}=0$, we may assume without loss of generality that $\alpha_{n}<\|A\|^{-1}$, for any $n \geq 1$. Let us define a mapping $T_{n}: H \rightarrow H$ provided by

$$
T_{n} x:=\alpha_{n} \gamma f(x)+\left(I-\alpha_{n} A\right) \frac{1}{t_{n}} \int_{0}^{t_{n}} T(s) x d s, \quad \forall n \geq 1 .
$$


An application of Lemma 2.1 yields that

$$
\begin{aligned}
\left\langle T_{n} x-T_{n} y, x-y\right\rangle & =\left\langle\left(I-\alpha_{n} A\right) \frac{1}{t_{n}} \int_{0}^{t_{n}}[T(s) x-T(s) y] d s, x-y\right\rangle+\alpha_{n} \gamma\langle f(x)-f(y), x-y\rangle \\
& \leq\left\|I-\alpha_{n} A\right\|\|x-y\|^{2}+\alpha_{n} \gamma\left(\|x-y\|^{2}-\phi(\|x-y\|)\|x-y\|\right) \\
& \leq\left[1-\alpha_{n}(\bar{\gamma}-\gamma)\right]\|x-y\|^{2}-\alpha_{n} \gamma \phi(\|x-y\|)\|x-y\| \\
& \leq\|x-y\|^{2}-\alpha_{n} \gamma \phi(\|x-y\|)\|x-y\|,
\end{aligned}
$$

and thus $T_{n}$ is $\phi$-strongly pseudocontractive and strongly continuous. It follows from Lemma 2.2 that $T_{n}$ has a unique fixed point (say) $x_{n} \in H$, that is, $\left\{x_{n}\right\}$ generated by (1.11) is well defined.

Taking $p \in F(\Gamma)$, we have

$$
\begin{aligned}
\left\|x_{n}-p\right\|^{2} & =\alpha_{n}\left\langle\gamma f\left(x_{n}\right)-A p, x_{n}-p\right\rangle+\left\langle\left(I-\alpha_{n} A\right) \frac{1}{t_{n}} \int_{0}^{t_{n}}\left[T(s) x_{n}-p\right] d s, x_{n}-p\right\rangle \\
& \leq \alpha_{n}\left\langle\gamma f\left(x_{n}\right)-\gamma f(p), x_{n}-p\right\rangle+\alpha_{n}\left\langle\gamma f(p)-A p, x_{n}-p\right\rangle+\left\|I-\alpha_{n} A\right\|\left\|x_{n}-p\right\|^{2} \\
& \leq\left[1-\alpha_{n}(\bar{\gamma}-\gamma)\right]\left\|x_{n}-p\right\|^{2}-\alpha_{n} \gamma \phi\left(\left\|x_{n}-p\right\|\right)\left\|x_{n}-p\right\|+\alpha_{n}\|\gamma f(p)-A p\|\left\|x_{n}-p\right\|
\end{aligned}
$$

and so

$$
(\bar{\gamma}-\gamma)\left\|x_{n}-p\right\|+\gamma \phi\left(\left\|x_{n}-p\right\|\right) \leq\|\gamma f(p)-A p\|
$$

This implies that $\left\|x_{n}-p\right\| \leq \phi^{-1}(\|\gamma f(p)-A p\| / \gamma)$ and $\left\{x_{n}\right\}$ is bounded.

We denote $z_{n}=\left(1 / t_{n}\right) \int_{0}^{t_{n}} T(s) x_{n} d s$ and have $\left\|z_{n}-p\right\| \leq\left\|x_{n}-p\right\|$, for any $p \in F(\Gamma)$. Since $\left\{x_{n}\right\}$ and $\left\{z_{n}\right\}$ are bounded, it follows from the Lipschitzian conditions of $\Gamma$ and $f$ that $\left\{A z_{n}\right\}$ and $\left\{f\left(x_{n}\right)\right\}$ are two bounded sequences. Therefore,

$$
\left\|x_{n}-z_{n}\right\|=\alpha_{n}\left\|\gamma f\left(x_{n}\right)-A z_{n}\right\| \longrightarrow 0
$$

Let

$$
C=\left\{x \in H:\|x-p\| \leq \phi^{-1}\left(\frac{\|\gamma f(p)-A p\|}{\gamma}\right)\right\} .
$$

Since $t_{n} \rightarrow \infty, C$ is a nonempty bounded closed convex subset and $T(s)$-invariant (i.e., $T(s) C$ is a subset of $C$ ), it follows from Lemma 2.4 that

$$
\lim _{n \rightarrow \infty}\left\|z_{n}-T(s) z_{n}\right\|=0, \quad \forall s \geq 0
$$


For each $s \geq 0$, we know that

$$
\begin{aligned}
\left\|x_{n}-T(s) x_{n}\right\| & \leq\left\|x_{n}-z_{n}\right\|+\left\|z_{n}-T(s) z_{n}\right\|+\left\|T(s) z_{n}-T(s) x_{n}\right\| \\
& \leq 2\left\|x_{n}-z_{n}\right\|+\left\|z_{n}-T(s) z_{n}\right\| .
\end{aligned}
$$

Consequently, we have from formulas (3.7) and (3.9) that

$$
\lim _{n \rightarrow \infty}\left\|x_{n}-T(s) x_{n}\right\|=0, \quad \forall s \geq 0 .
$$

Because $\left\{x_{n}\right\}$ is bounded, there exists a subsequence $\left\{x_{n_{k}}\right\} \subset\left\{x_{n}\right\}$ which converges weakly to some $x^{*}$. It is known from Lemma 2.3 that $I-T(s)$ is demiclosed at zero for each $s \geq 0$, where $I$ is the identity mapping on $H$. Thus, $x^{*} \in F(\Gamma)$ follows readily.

In addition, by (1.11) and Lemma 2.1, we observe

$$
\begin{aligned}
\left\|x_{n}-x^{*}\right\|^{2} & =\alpha_{n}\left\langle\gamma f\left(x_{n}\right)-A x^{*}, x_{n}-x^{*}\right\rangle+\left\langle\left(I-\alpha_{n} A\right) \frac{1}{t_{n}} \int_{0}^{t_{n}}\left[T(s) x_{n}-x^{*}\right] d s, x_{n}-x^{*}\right\rangle \\
& \leq \alpha_{n}\left\langle\gamma f\left(x_{n}\right)-\gamma f\left(x^{*}\right), x_{n}-x^{*}\right\rangle+\alpha_{n}\left\langle\gamma f\left(x^{*}\right)-A x^{*}, x_{n}-x^{*}\right\rangle+\left\|I-\alpha_{n} A\right\|\left\|x_{n}-x^{*}\right\|^{2} \\
& \leq\left[1-\alpha_{n}(\bar{\gamma}-\gamma)\right]\left\|x_{n}-x^{*}\right\|^{2}-\alpha_{n} \gamma \phi\left(\left\|x_{n}-x^{*}\right\|\right)\left\|x_{n}-x^{*}\right\|+\alpha_{n}\left\langle\gamma f\left(x^{*}\right)-A x^{*}, x_{n}-x^{*}\right\rangle,
\end{aligned}
$$

which implies that

$$
\gamma \phi\left(\left\|x_{n}-x^{*}\right\|\right)\left\|x_{n}-x^{*}\right\| \leq\left\langle\gamma f\left(x^{*}\right)-A x^{*}, x_{n}-x^{*}\right\rangle .
$$

This means that $\left\{x_{n_{k}}\right\}$ converges strongly to $x^{*}$. If there exists another subsequence $\left\{x_{n_{j}}\right\} \subset$ $\left\{x_{n}\right\}$ which converges weakly to $y^{*}$, then from (3.11) and (3.13) we know that $\left\{x_{n_{j}}\right\}$ converges strongly to $y^{*} \in F(\Gamma)$. For any $p \in F(\Gamma)$, it follows from (1.11) that

$$
\begin{aligned}
\left\langle A z_{n}-\gamma f\left(x_{n}\right), x_{n}-p\right\rangle & =\frac{1}{\alpha_{n}}\left\langle z_{n}-x_{n}, x_{n}-p\right\rangle \\
& =\frac{1}{\alpha_{n}}\left(\left\langle\frac{1}{t_{n}} \int_{0}^{t_{n}}\left[T(s) x_{n}-p\right] d s, x_{n}-p\right\rangle-\left\|x_{n}-p\right\|^{2}\right)
\end{aligned}
$$

$\leq 0$.

The convergence of sequences $\left\{x_{n_{k}}\right\}$ and $\left\{x_{n_{j}}\right\}$ yields that

$$
\begin{aligned}
& \left\langle A x^{*}-\gamma f\left(x^{*}\right), x^{*}-y^{*}\right\rangle \leq 0, \\
& \left\langle A y^{*}-\gamma f\left(y^{*}\right), y^{*}-x^{*}\right\rangle \leq 0 .
\end{aligned}
$$


Thus,

$$
\begin{aligned}
\bar{r}\left\|x^{*}-y^{*}\right\|^{2} & \leq\left\langle A\left(x^{*}-y^{*}\right), x^{*}-y^{*}\right\rangle \\
& \leq r\left\langle f\left(x^{*}\right)-f\left(y^{*}\right), x^{*}-y^{*}\right\rangle \\
& \leq r\left\|x^{*}-y^{*}\right\|^{2}-r \phi\left(\left\|x^{*}-y^{*}\right\|\right)\left\|x^{*}-y^{*}\right\| .
\end{aligned}
$$

This implies that $x^{*}=y^{*}$. Therefore, $\left\{x_{n}\right\}$ converges strongly to $x^{*} \in F(\Gamma)$. From (3.14) and the deduction above, we know that $x^{*}$ is also the unique solution to VI (3.2). This completes the proof.

Theorem 3.2. Let $\Gamma:=\{T(s): s \geq 0\}$ be a nonexpansive semigroup on $H$ and $f: H \rightarrow H$ be an $L_{f}$-Lipschitzian pseudocontractive mapping. Let $A$ be a strongly positive and linear bounded operator on $H$ with coefficient $\bar{\gamma}$. Then for any $0<\gamma<\bar{\gamma}$, the sequence $\left\{x_{n}\right\}$ generated by (1.11) is well defined. Suppose that

$$
\lim _{t \rightarrow \infty} \alpha_{n}=0, \quad \lim _{n \rightarrow \infty} t_{n}=\infty
$$

Then the sequence $\left\{x_{n}\right\}$ converges strongly as $n \rightarrow \infty$ to a common fixed point $x^{*} \in F(\Gamma)$ that is the unique solution in $F(\Gamma)$ to $V I(3.2)$.

Proof. Similar to the proof of Theorem 3.1, we can verify that the sequence $\left\{x_{n}\right\}$ generated by (1.11) is well defined,

$$
\begin{aligned}
\left\|x_{n}-p\right\| \leq & \frac{1}{\bar{\gamma}-\gamma}\|\gamma f(p)-A p\| \quad \text { for a fixed } p \in F(\Gamma), \\
& \lim _{n \rightarrow \infty}\left\|x_{n}-T(s) x_{n}\right\|=0, \quad \forall s \geq 0 .
\end{aligned}
$$

Thus, $\left\{x_{n}\right\}$ is bounded and so there exists a subsequence $\left\{x_{n_{k}}\right\} \subset\left\{x_{n}\right\}$ which converges weakly to some $x^{*}$. It is obvious that $x^{*} \in F(\Gamma)$.

In addition, by (1.11) and Lemma 2.1, we can show that

$$
\left\|x_{n}-x^{*}\right\|^{2} \leq \frac{1}{\bar{\gamma}-\gamma}\left\langle\gamma f\left(x^{*}\right)-A x^{*}, x_{n}-x^{*}\right\rangle .
$$

This means that $\left\{x_{n_{k}}\right\}$ converges strongly to $x^{*}$. The rest of the proof is almost the same as Theorem 3.1. This completes the proof.

Remark 3.3. (1) Theorems 3.1 and 3.2 improve and generalize Theorem 3.1 of [5] from contractive mapping to $\phi$-strongly pseudocontractive mapping and pseudocontractive mapping, respectively. (2) Theorems 3.1 and 3.2 also improve and generalize Theorem 3.2 of [6] from nonexpansive mapping to nonexpansive semigroup, and from contractive mapping to $\phi$-strongly pseudocontractive mapping and pseudocontractive mapping, respectively.

A strong mean convergence theorem for nonexpansive mappings was first established by Baillon [17], and later generalized to that for nonlinear semigroup (see, e.g., [8]). It is clear 
that Theorems 3.1 and 3.2 are valid for nonexpansive mappings. Thus, we have the following mean ergodic assertions of general viscosity iteration process for nonexpansive mappings in Hilbert spaces.

Corollary 3.4. Let $H, f, A$ be as in Theorem 3.1, $T: H \rightarrow H$ be a nonexpansive mapping such that the fixed points set $F$ of $T$ is nonempty. Let $\left\{\alpha_{n}\right\} \subset(0,1]$ be a real sequence such that $\lim _{n \rightarrow \infty} \alpha_{n}=0$. Then for any $0<\gamma \leq \bar{\gamma}$, there exists a unique $\left\{x_{n}\right\}$ such that

$$
x_{n}=\left(I-\alpha_{n} A\right) \frac{1}{n+1} \sum_{j=0}^{n} T^{j} x_{n}+\alpha_{n} \gamma f\left(x_{n}\right), \quad \forall n \geq 0 .
$$

Moreover, the sequence $\left\{x_{n}\right\}$ generated by (3.20) converges strongly as $n \rightarrow \infty$ to a common fixed point $x^{*} \in F$ that is the unique solution in $F$ to variational inequality (VI):

$$
\left\langle\gamma f\left(x^{*}\right)-A x^{*}, x^{*}-p\right\rangle \geq 0, \quad \forall p \in F
$$

Corollary 3.5. Let $H, f, A$ be as in Theorem 3.2, $T: H \rightarrow H$ be a nonexpansive mapping such that the fixed points set $F$ of $T$ is nonempty. Let $\left\{\alpha_{n}\right\} \subset(0,1]$ be a real sequence such that $\lim _{n \rightarrow \infty} \alpha_{n}=0$. Then for any $0<\gamma<\bar{\gamma}$, there exists a unique $\left\{x_{n}\right\}$ satisfying (3.20). Moreover, the sequence $\left\{x_{n}\right\}$ generated by (3.20) converges strongly as $n \rightarrow \infty$ to a common fixed point $x^{*} \in F$ that is the unique solution in F to VI (3.21).

We now turn to discuss the convergence of general implicit viscosity iteration process (1.13) constructed from a nonexpansive semigroup $\Gamma:=\{T(t): t \geq 0\}$.

Theorem 3.6. Let $\Gamma:=\{T(t): t \geq 0\}$ be a nonexpansive semigroup on $H$ and $f: H \rightarrow H$ be an $L_{f}$-Lipschitzian $\phi$-strongly pseudocontractive mapping with $\lim _{t \rightarrow+\infty} \phi(t)=+\infty$. Let $A$ be a strongly positive and linear bounded operator with coefficient $\bar{\gamma}$. Then for any $0<\gamma \leq \bar{\gamma}$, the sequence $\left\{x_{n}\right\}$ generated by (1.13) is well defined. Suppose that for any bounded subset $K \subset H$,

$$
\begin{gathered}
\limsup _{s \rightarrow 0}\|T(s) x-x\|=0, \\
\lim _{n \rightarrow \infty} t_{n}=\lim _{n \rightarrow \infty} \frac{\alpha_{n}}{t_{n}}=0 .
\end{gathered}
$$

Then the sequence $\left\{x_{n}\right\}$ converges strongly as $n \rightarrow \infty$ to a common fixed point $x^{*} \in F(\Gamma)$ that is the unique solution in $F(\Gamma)$ to $V I$ (3.2).

Proof. Since $\lim _{n \rightarrow \infty} \alpha_{n}=0$, we assume without loss of generality that $\alpha_{n}<\|A\|^{-1}$, for any $n \geq 1$. Let

$$
T_{n}^{f} x:=\alpha_{n} \gamma f(x)+\left(I-\alpha_{n} A\right) T\left(t_{n}\right) x, \quad \forall n \geq 1 .
$$


Fixed Point Theory and Applications

By Lemma 2.2, we know

$$
\begin{aligned}
\left\langle T_{n}^{f} x-T_{n}^{f} y, x-y\right\rangle & =\left\langle\left(I-\alpha_{n} A\right)\left(T\left(t_{n}\right) x-T\left(t_{n}\right) y\right), x-y\right\rangle+\alpha_{n} \gamma\langle f(x)-f(y), x-y\rangle \\
& \leq\left\|I-\alpha_{n} A\right\|\|x-y\|^{2}+\alpha_{n} \gamma\left(\|x-y\|^{2}-\phi(\|x-y\|)\|x-y\|\right) \\
& \leq\|x-y\|^{2}-\alpha_{n} \gamma \phi(\|x-y\|)\|x-y\|,
\end{aligned}
$$

and thus $T_{n}^{f}$ is $\phi$-strongly pseudocontractive and strongly continuous. It follows from Lemma 2.2 that $T_{n}^{f}$ has a unique fixed point (say) $x_{n} \in H$, that is, $\left\{x_{n}\right\}$ generated by (1.13) is well defined.

Taking $p \in F(\Gamma)$, we note

$$
\begin{aligned}
\left\|x_{n}-p\right\|^{2} & =\alpha_{n}\left\langle\gamma f\left(x_{n}\right)-A p, x_{n}-p\right\rangle+\left\langle\left(I-\alpha_{n} A\right)\left(T\left(t_{n}\right) x_{n}-p\right), x_{n}-p\right\rangle \\
& \leq \alpha_{n}\left\langle\gamma f\left(x_{n}\right)-\gamma f(p), x_{n}-p\right\rangle+\alpha_{n}\left\langle\gamma f(p)-A p, x_{n}-p\right\rangle+\left\|I-\alpha_{n} A\right\|\left\|x_{n}-p\right\|^{2} \\
& \leq\left[1-\alpha_{n}(\bar{\gamma}-\gamma)\right]\left\|x_{n}-p\right\|^{2}-\alpha_{n} \gamma \phi\left(\left\|x_{n}-p\right\|\right)\left\|x_{n}-p\right\|+\alpha_{n}\|\gamma f(p)-A p\|\left\|x_{n}-p\right\|,
\end{aligned}
$$

and so $\left\|x_{n}-p\right\| \leq \phi^{-1}(\|\gamma f(p)-A p\| / \gamma)$, the sequence $\left\{x_{n}\right\}$ is bounded. It follows from the Lipschitzian conditions of $\Gamma$ and $f$ that $\left\{A T\left(t_{n}\right) x_{n}\right\}$ and $\left\{f\left(x_{n}\right)\right\}$ are bounded. (1.13) implies that

$$
\left\|x_{n}-T\left(t_{n}\right) x_{n}\right\|=\alpha_{n}\left\|\gamma f\left(x_{n}\right)-A T\left(t_{n}\right) x_{n}\right\| \longrightarrow 0 .
$$

For any given $t>0$,

$$
\begin{aligned}
\left\|x_{n}-T(t) x_{n}\right\| & =\sum_{k=0}^{\left[t / t_{n}\right]-1}\left\|T\left((k+1) t_{n}\right) x_{n}-T\left(k t_{n}\right) x_{n}\right\|+\left\|T(t) x_{n}-T\left(\left[\frac{t}{t_{n}}\right] t_{n}\right) x_{n}\right\| \\
& \leq\left[\frac{t}{t_{n}}\right]\left\|x_{n}-T\left(t_{n}\right) x_{n}\right\|+\left\|T\left(t-\left[\frac{t}{t_{n}}\right] t_{n}\right) x_{n}-x_{n}\right\| \\
& \leq t \frac{\alpha_{n}}{t_{n}}\left\|A T\left(t_{n}\right) x_{n}-r f\left(x_{n}\right)\right\|+\max \left\{\left\|T(s) x_{n}-x_{n}\right\|: 0 \leq s \leq t_{n}\right\},
\end{aligned}
$$

where $\left[t / t_{n}\right]$ is the integral part of $t / t_{n}$. Since $\lim _{n \rightarrow \infty}\left(\alpha_{n} / t_{n}\right)=0$ and $T(\cdot) x: R^{+} \rightarrow H$ is continuous for any $x \in H$, it follows from (3.22) that

$$
\lim _{n \rightarrow \infty}\left\|x_{n}-T(t) x_{n}\right\|=0 \quad \forall t \geq 0
$$

Because $\left\{x_{n}\right\}$ is bounded, there exists a subsequence $\left\{x_{n_{k}}\right\} \subset\left\{x_{n}\right\}$ which converges weakly to some $x^{*}$. By Lemma 2.3, we know that $x^{*} \in F(\Gamma)$. 
In addition, by (1.13) and Lemma 2.1, we observe

$$
\begin{aligned}
\left\|x_{n}-x^{*}\right\|^{2}= & \alpha_{n}\left\langle\gamma f\left(x_{n}\right)-A x^{*}, x_{n}-x^{*}\right\rangle+\left\langle\left(I-\alpha_{n} A\right)\left(T\left(t_{n}\right) x_{n}-x^{*}\right), x_{n}-x^{*}\right\rangle \\
\leq & \alpha_{n}\left\langle\gamma f\left(x_{n}\right)-\gamma f\left(x^{*}\right), x_{n}-x^{*}\right\rangle \\
& +\alpha_{n}\left\langle\gamma f\left(x^{*}\right)-A x^{*}, x_{n}-x^{*}\right\rangle+\left\|I-\alpha_{n} A\right\|\left\|x_{n}-x^{*}\right\|^{2} \\
\leq & {\left[1-\alpha_{n}(\bar{\gamma}-\gamma)\right]\left\|x_{n}-x^{*}\right\|^{2}-\alpha_{n} \gamma \phi\left(\left\|x_{n}-x^{*}\right\|\right)\left\|x_{n}-x^{*}\right\| } \\
& +\alpha_{n}\left\langle\gamma f\left(x^{*}\right)-A x^{*}, x_{n}-x^{*}\right\rangle,
\end{aligned}
$$

which implies that

$$
\gamma \phi\left(\left\|x_{n}-x^{*}\right\|\right)\left\|x_{n}-x^{*}\right\| \leq\left\langle\gamma f\left(x^{*}\right)-A x^{*}, x_{n}-x^{*}\right\rangle .
$$

For any $p \in F(\Gamma)$, it follows from (1.13) that

$$
\begin{aligned}
\left\langle A T\left(t_{n}\right) x_{n}-\gamma f\left(x_{n}\right), x_{n}-p\right\rangle & =\frac{1}{\alpha_{n}}\left\langle T\left(t_{n}\right) x_{n}-x_{n}, x_{n}-p\right\rangle \\
& =\frac{1}{\alpha_{n}}\left(\left\langle T\left(t_{n}\right) x_{n}-p, x_{n}-p\right\rangle-\left\|x_{n}-p\right\|^{2}\right) \\
& \leq 0 .
\end{aligned}
$$

The rest of the proof is the same as Theorem 3.1. This completes the proof.

To illustrate Theorem 3.6, we give the following example concerned with a nonexpansive semigroup $\Gamma:=\{T(t): t \geq 0\}$ on $H$.

Example 3.7. Let $H$ be a Hilbert space. For each given $t \geq 0$, let $T(t): H \rightarrow H$ be defined by

$$
T(t) x=e^{-t} x, \quad \forall x \in H .
$$

Then it is easy to check that $\Gamma:=\{T(t): t \geq 0\}$ is a nonexpansive semigroup satisfying (3.22) and $F(\Gamma)$ is a singleton $\{\theta\}$, where $\theta$ is the zero point in $H$.

Combining the proofs of Theorems 3.2 and 3.6, we can easily conclude the following result.

Theorem 3.8. Let $f: H \rightarrow H$ be an $L_{f}$-Lipschitzian pseudocontractive mapping and $\Gamma:=\{T(t)$ : $t \geq 0\}$ be a nonexpansive semigroup on $H$ such that (3.22) holds. Let $A$ be a strongly positive and linear bounded operator with coefficient $\bar{\gamma}$. Then for any $0<\gamma<\bar{\gamma}$, the sequence $\left\{x_{n}\right\}$ generated by (1.13) is well defined. Suppose that

$$
\lim _{n \rightarrow \infty} t_{n}=\lim _{n \rightarrow \infty} \frac{\alpha_{n}}{t_{n}}=0 .
$$


Then the sequence $\left\{x_{n}\right\}$ converges strongly as $n \rightarrow \infty$ to a common fixed point $x^{*} \in F(\Gamma)$ that is the unique solution in $F(\Gamma)$ to $V I$ (3.2).

Remark 3.9. (1) Theorems 3.6 and 3.8 improve and generalize Theorem 3.2 of [6] from nonexpansive mapping to nonexpansive semigroup, and from contraction mapping to $\phi$ strongly pseudocontractive mapping and pseudocontractive mapping, respectively. (2) If $A$ is the identity mapping $I, f$, and $\Gamma$ are restricted on a nonempty closed convex subset in $H$, then Theorem 3.6 of [4] follows by Theorems 3.6 and 3.8. So, Theorems 3.6 and 3.8 generalize Theorem 3.6 of [4].

\section{Acknowledgments}

The authors are grateful to Professor J. C. Yao and the referees for valuable comments and suggestions. This work was supported by The Key Program of NSFC (Grant no. 70831005), the National Natural Science Foundation of China (10671135, 11026063), and the Open Fund (PLN0904) of State Key Laboratory of Oil and Gas Reservoir Geology and Exploitation (Southwest Petroleum University).

\section{References}

[1] S.-S. Chang, "Viscosity approximation methods for a finite family of nonexpansive mappings in Banach spaces," Journal of Mathematical Analysis and Applications, vol. 323, no. 2, pp. 1402-1416, 2006.

[2] R. Chen and H. He, "Viscosity approximation of common fixed points of nonexpansive semigroups in Banach space," Applied Mathematics Letters, vol. 20, no. 7, pp. 751-757, 2007.

[3] J. S. Jung, "Viscosity approximation methods for a family of finite nonexpansive mappings in Banach spaces," Nonlinear Analysis: Theory, Methods \& Applications, vol. 64, no. 11, pp. 2536-2552, 2006.

[4] X. Li, J. K. Kim, and N. Huang, "Viscosity approximation of common fixed points for L-Lipschitzian semigroup of pseudocontractive mappings in Banach spaces," Journal of Inequalities and Applications, vol. 2009, Article ID 936121, 16 pages, 2009.

[5] S. Li, L. Li, and Y. Su, "General iterative methods for a one-parameter nonexpansive semigroup in Hilbert space," Nonlinear Analysis: Theory, Methods E Applications, vol. 70, no. 9, pp. 3065-3071, 2009.

[6] G. Marino and H.-K. Xu, "A general iterative method for nonexpansive mappings in Hilbert spaces," Journal of Mathematical Analysis and Applications, vol. 318, no. 1, pp. 43-52, 2006.

[7] S. Reich, "Strong convergence theorems for resolvents of accretive operators in Banach spaces," Journal of Mathematical Analysis and Applications, vol. 75, no. 1, pp. 287-292, 1980.

[8] S. Reich, "A note on the mean ergodic theorem for nonlinear semigroups," Journal of Mathematical Analysis and Applications, vol. 91, no. 2, pp. 547-551, 1983.

[9] N. Shahzad, "Approximating fixed points of non-self nonexpansive mappings in Banach spaces," Nonlinear Analysis: Theory, Methods E Applications, vol. 61, no. 6, pp. 1031-1039, 2005.

[10] T. Shimizu and W. Takahashi, "Strong convergence to common fixed points of families of nonexpansive mappings," Journal of Mathematical Analysis and Applications, vol. 211, no. 1, pp. 71-83, 1997.

[11] Y. Song, R. Chen, and H. Zhou, "Viscosity approximation methods for nonexpansive mapping sequences in Banach spaces," Nonlinear Analysis: Theory, Methods E Applications, vol. 66, no. 5, pp. 1016-1024, 2007.

[12] Y. Yao, Y.-C. Liou, and R. Chen, "A general iterative method for an infinite family of nonexpansive mappings," Nonlinear Analysis: Theory, Methods E Applications, vol. 69, no. 5-6, pp. 1644-1654, 2008.

[13] H.-K. Xu, "Viscosity approximation methods for nonexpansive mappings," Journal of Mathematical Analysis and Applications, vol. 298, no. 1, pp. 279-291, 2004.

[14] H.-K. Xu and R. G. Ori, "An implicit iteration process for nonexpansive mappings," Numerical Functional Analysis and Optimization, vol. 22, no. 5-6, pp. 767-773, 2001.

[15] H. Zegeye, N. Shahzad, and T. Mekonen, "Viscosity approximation methods for pseudocontractive mappings in Banach spaces," Applied Mathematics and Computation, vol. 185, no. 1, pp. 538-546, 2007. 
[16] Z. Liu and S. M. Kang, "Convergence theorems for $\phi$-strongly accretive and $\phi$-hemicontractive operators," Journal of Mathematical Analysis and Applications, vol. 253, no. 1, pp. 35-49, 2001.

[17] J.-B. Baillon, “Un théorème de type ergodique pour les contractions non linéaires dans un espace de Hilbert," Comptes Rendus de l'Académie des sciences, vol. 280, no. 22, pp. A1511-A1514, 1975. 